Section Editor Mitchell S.V. Elkind, MD, MS

\title{
A woman with rapidly progressive apraxia
}

Peter Pressman, MD

Eileen H. Bigio, MD

Darren Gitelman, MD

Cindy Zadikoff, MD

Correspondence to

Dr. Pressman:

p-pressman@northwestern.edu
Supplemental data at www.neurology.org
A 56-year-old woman presented with changes in balance, handwriting, and thinking. Approximately 1 year before her first visit, the patient developed difficulty walking, which caused multiple falls without serious injury. She also developed bilateral upper-extremity tremors that worsened with movement. At the time of her visit, she could barely sign her name.

Approximately 4 months before her first visit, the patient's family noticed she was having more difficulty speaking, causing frequent pauses in conversation. Sentence structure in her e-mails was abnormal but her family believed that her comprehension was intact. She was still able to do most of her activities of daily living, but only cooked simple meals, and had stopped driving because of a minor car accident.

The patient's medical history was notable for breast cancer, treated with mastectomy, chemotherapy, and radiation 7 years prior. She also had kidney stones necessitating a total nephrectomy after failed lithotripsy, and experienced urinary incontinence and constipation. Medications included letrozole $2.5 \mathrm{mg}$ daily, polyethylene glycol $17 \mathrm{~g}$ daily, and solifenacin $10 \mathrm{mg}$ daily. She had a family history of dementia in her mother when she was in the eighth decade of life, but no other family history of dementia or neurodegenerative illness.

At the time of her first visit to a neurologist, the patient's vital signs were normal. On cognitive testing, the patient's Mini-Mental State Examination score was $28 / 30$, with difficulties in figure copying and writing that were both attributable to a tremor. Further cognitive testing showed decreased naming and difficulty understanding a syntactically complex sentence. Spelling was reduced for longer words. She had some right/ left confusion. Ideomotor, limb kinetic, and oral apraxias were prominent, as were bilateral palmar grasp responses. Gegenhalten was present. Her cranial nerve examination was notable for saccadic pursuits. On motor examination, her strength was intact. She had postural and action tremors bilaterally. She had severe impairment of fine finger movements and rapid alternating movements due to decreased amplitude and frequent arrests of movement. Her gait was notable for decreased arm swing and en bloc turning.
The patient was referred to a movement disorders specialist who also noted extrapyramidal signs of bradykinesia and postural instability, apraxia, and myoclonus, with apraxia being the dominant component (video).

Question 1: How would you localize the degenerative process? The patient's examination is notable for speech difficulty and apraxia. Apraxia may localize to frontal or parietal lobes. Left parietal lobe lesions, in particular, have been associated with buccofacial and bilateral limb apraxia. ${ }^{1,2}$ These apraxias may also be associated with conduction or Broca aphasia, which may be pertinent to this patient's word-finding difficulty and trouble with complex sentences. ${ }^{3}$ She also had bradykinesia suggesting involvement of the extrapyramidal system.

Question 2: What is your leading clinical diagnosis? Given her prominent apraxia, postural tremor, and bradykinesia, the patient was diagnosed as having a corticobasal syndrome (CBS). ${ }^{4}$ Whereas corticobasal degeneration implies a unique pathology involving a 4-repeat tauopathy, CBS describes the clinical presentation and has an expanded pathologic differential diagnosis (table e-1 on the Neurology ${ }^{\circledR}$ Web site at www.neurology.org). For example, cases of CBS have shown Alzheimer pathology, Lewy body disease, or progressive supranuclear palsy at autopsy.,

CBS classically begins as a unilateral akinetic-rigid disorder with associated localizing cortical findings that may include cortical sensory loss, alien limb phenomenon, and pyramidal findings. Apraxia is frequently associated with CBS. Patients with CBS may also first present with cognitive problems including a language disorder, and later develop motor symptoms. ${ }^{7}$

Given the rapidity of her decline, other disorders to consider that have also presented with the clinical picture of CBS include a paraneoplastic syndrome or prion disease such as Creutzfeldt-Jakob disease (CJD). Cases of prion disease presenting with abnormal movements, myoclonus, aphasia, and apraxia are well described. ${ }^{8}$

Question 3: What tests would you like to order and review? MRI can be suggestive of CBS if there is asymmetrical cortical atrophy. ${ }^{9}$ For other diagnoses, MRI scans show midbrain atrophy in progressive supranuclear 
Figure 1 Fluid-attenuated inversion recovery MRI of the patient's brain in the axial plane

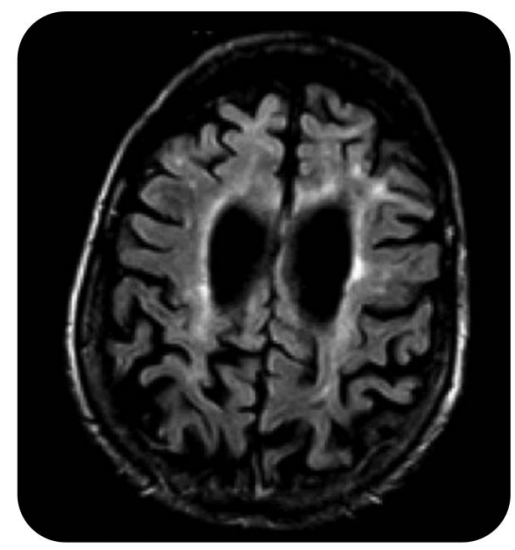

There are confluent T2 hyperintensities involving subcortical white matter of the superior frontal gyri bilaterally and central to the motor strip, with additional T2 hyperintensities in periventricular white matter and atrophy of the paracentral lobules bilaterally.

palsy. MRI has a sensitivity of $91 \%$ to $92 \%$, and specificity of $94 \%$ to $95 \%$ for CJD. ${ }^{8}$ MRI findings suggestive of CJD include cortical ribboning or basal ganglia hyperintensity on fluid-attenuated inversion recovery and diffusion-weighted images with corresponding low signal on the $\mathrm{ADC}$ sequences. Conventional MRI scans are neither sensitive nor specific for the diagnosis of Alzheimer disease or Lewy body dementia.

An MRI of the brain done 6 months before her first examination in our clinic demonstrated mild vermian atrophy with some midline frontal atrophy. The lateral and third ventricles were prominent, with periventricular and subcortical T2 hyperintensities. The body and splenium of the corpus callosum were markedly

Figure 2 Coronal section at the level of the anterior commissure

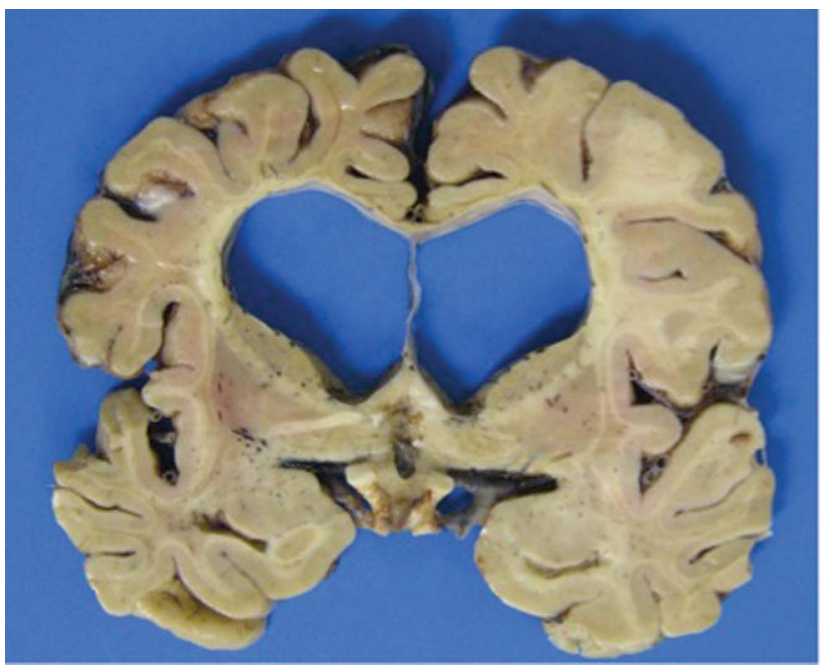

Note marked attenuation of subcortical white matter. thinned. The caudate nuclei were also thinned bilaterally (figure 1).

Laboratory studies of serum and CSF are also indicated in the workup of a rapidly progressive neurodegenerative process. White and red blood cell counts, glucose, and protein were normal in her CSF. The venereal disease research laboratory test, oligoclonal bands, myelin basic protein, cytology, and cryptococcal antigen were all negative. CSF 14-3-3 protein was indeterminate. A paraneoplastic panel including $\mathrm{Hu}, \mathrm{Mal}$, Ma2, Yo, Ri, LEMS, CV2, VGKC, and Zic4 antibodies was negative. Blood tests including thyroglobulin, thyroid peroxidase, thyroid stimulating hormone, vitamin B1, Lyme disease antibodies, antigliadin immunoglobulin $A$, immunoglobulin $G$, serum protein electrophoresis, HIV-1 and -2, methylmalonic acid, erythrocyte sedimentation rate, antinuclear antibody screen, B12, folate, and hemoglobin A1c were all normal.

A 30-minute EEG demonstrated bilateral slowing that was most prominent over the left hemisphere. A PET scan of the brain demonstrated minimal asymmetrical areas of hypometabolism in the left parietal lobe.

Question 4: What therapies might you recommend? Aside from her cognitive deficits, the patient's dominant problem was her apraxia, the medical treatment of which is limited. The patient also had myoclonus, which can be best treated with trials of levetiracetam, clonazepam, or valproic acid. ${ }^{10}$ Carbidopa-levodopa for the associated parkinsonism can also be tried but is typically much less effective than in its use for idiopathic Parkinson disease.

She was started on levetiracetam for myoclonus with no change in her symptoms. It was subsequently discontinued. Clonazepam was also tried without success. A trial of carbidopa-levodopa showed no benefit, and was discontinued. Escitalopram was added for concomitant depression.

Question 5: What other steps should be taken in the care of a patient with incurable, advancing neurodegenerative disease? Over the course of 2 years, the patient deteriorated significantly. She became globally aphasic, and her difficulty walking progressed so that she required a wheelchair for mobility. She became increasingly apathetic and developed a pseudobulbar affect. Her examination was further marked by myoclonus in the right arm, with mild rigidity in all extremities and dystonic posturing in the left hand. She was unable to initiate eye movement without a head thrust.

Speech therapy was offered. A swallow study was normal. Hospice was notified and brain donation was discussed. The utility of a feeding tube was also discussed but was declined by the family. The patient was maintained on a diet of thickened liquids and pureed foods. While in hospice, she developed aspiration pneumonia and died 3 years after symptom onset. 
Figure 3 Marked white-matter rarefaction with neuroaxonal spheroid (open arrow) and glial cell with brownish pigment (arrow)

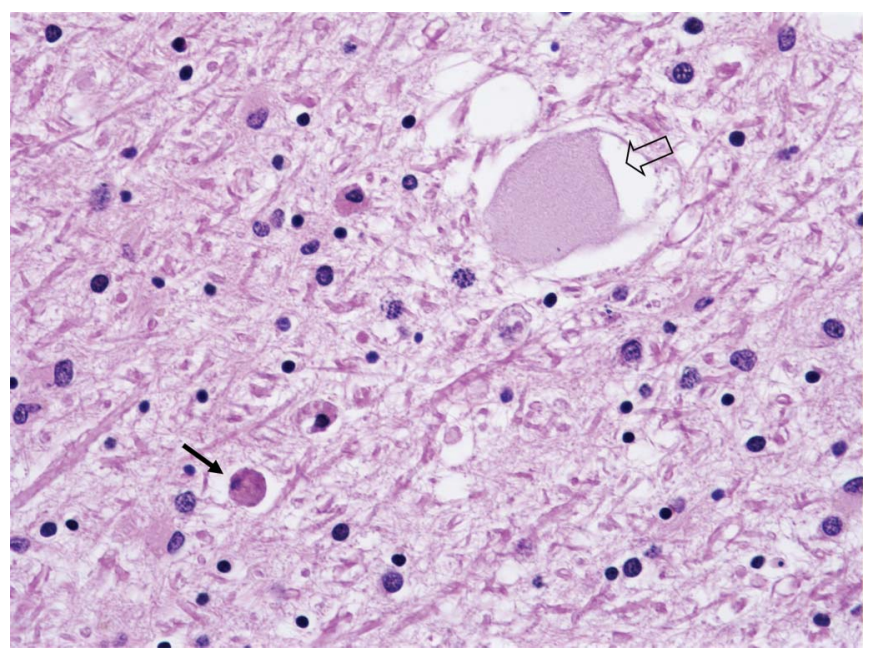

Hematoxylin \& eosin, 600× magnification.

Autopsy revealed a 1,190-g brain with moderate frontal and parietal and mild temporal atrophy. Coronal sections revealed severe dilatation of the lateral ventricles and severe attenuation of the subcortical white matter (figure 2). Microscopically, there was severe white-matter rarefaction with loss of both axons and myelin, and frequent neuroaxonal spheroids and pigmented glia and macrophages (figure 3). Spheroids were highlighted with a neurofilament immunostain (figure 4). Two separate neuropathologists confirmed the diagnosis of adult-onset leukodystrophy with neuroaxonal spheroids and pigmented glia.

DISCUSSION Adult-onset leukodystrophy with neuroaxonal spheroids, also known as hereditary diffuse

Figure 4 Neuroaxonal spheroids highlighted by neurofilament immunostain

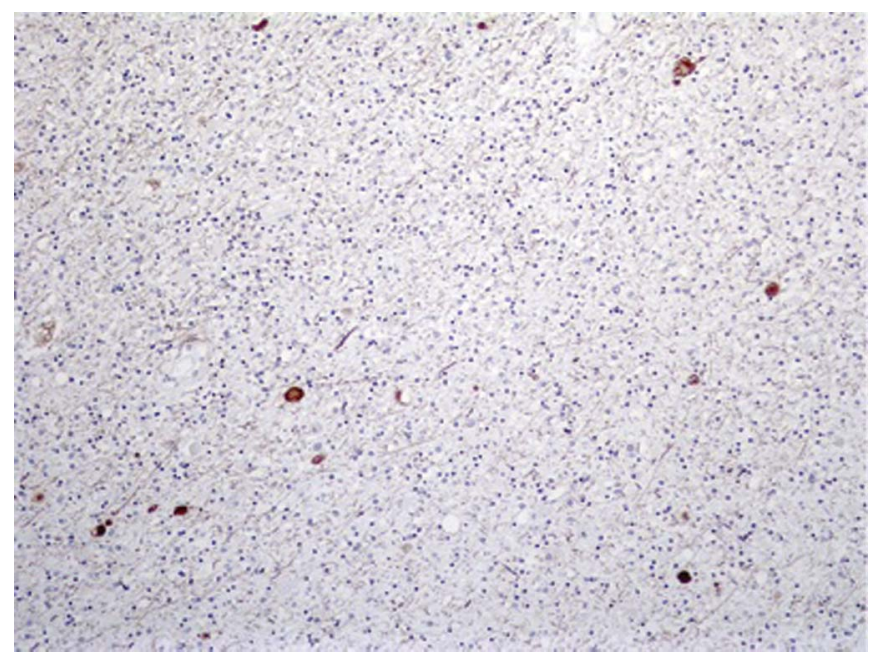

Neurofilament, $100 \times$ magnification. leukoencephalopathy with spheroids, is an uncommon disorder that usually demonstrates autosomal dominant inheritance. However, sporadic cases have been reported. A recent literature review reported that the age at onset varies from 15 to 78 years, with a mean of 42 years of age. Age of death averages 48 years, with a range of 17 to 89 years of age. The duration of symptoms ranged from 2 months to 34 years, with symptoms including dementia, apraxia, ataxia, urinary incontinence, and extrapyramidal symptoms. ${ }^{11}$ Depression, aggression, and psychotic features may also develop. The differential diagnosis includes frontotemporal dementia, corticobasal degeneration, and other leukoencephalopathies such as metachromatic leukodystrophy, cerebral autosomal dominant arteriopathy with subcortical infarcts and leukoencephalopathy, and Binswanger disease. ${ }^{11,12}$

The leukoencephalopathy is most severe in the frontal and temporal lobes, although the thalamus and rostral caudate may be mildly reduced in size, and the corticospinal tracts and basis of the pons may also be atrophic. This gray-matter involvement may reflect neuronal death due to lack of sustaining cortical/subcortical projecting fibers, or may also be due to white-matter damage to tracts that traverse these nuclei. ${ }^{12,13}$ Pre- and postcentral gyri tend to be most involved. U fibers are relatively spared. MRI demonstrates signal abnormality in bilateral white matter. The corpus callosum may be thinned, and cerebellar degeneration may be noted. The MRI findings are nonspecific, however. ${ }^{12}$

Earlier this year, heterozygous mutations in a gene encoding the tyrosine kinase domain of the colonystimulating factor receptor 1 (CSF1R) were associated with hereditary diffuse leukoencephalopathy with spheroids. ${ }^{14}$ The relationship between this gene and sporadic cases is less certain.

Before the recent discovery of the CSF1R mutation, the only way to confirm this diagnosis was by histopathology. Microscopy reveals widespread leukoencephalopathy with axonal spheroids and macrophages in affected white matter. The spheroids are best identified with Bielschowsky, Bodian, and antineurofilament immunostains. There is a pronounced loss of Purkinje cells in the cerebellum. At this time, supportive care is the only therapeutic option.

\section{AUTHOR CONTRIBUTIONS}

Dr. Pressman wrote the presented case report. Dr. Zadikoff treated the patient in this case report, provided references, and made several revisions to this case report. Dr. Bigio made the pathologic diagnosis for this patient, provided the pathologic description in the case report, provided references, and provided the pathologic figures for this case report. Dr. Gitelman treated the patient in this case report and made substantial revisions to this case report.

\section{ACKNOWLEDGMENT}

The authors are grateful to James M. Powers, MD, for review of this case and his confirmation of the pathologic diagnosis. 


\section{STUDY FUNDING}

No targeted funding reported.

\section{DISCLOSURE}

P. Pressman serves on the editorial team of the Residents and Fellows Section of Neurology $y^{\circledR}$, and writes for About.com. E. Bigio reports no disclosures. Dr. Gitelman is a consultant for EMD Serono. C. Zadikoff has served on the speakers' bureau/advisory board of Teva, Merz, Allergan, Ipsen, GSK, and US World Meds. Go to Neurology.org for full disclosures.

\section{REFERENCES}

1. Alexander M, Baker E, Naeser M, Kaplan E, Palumbo C. Neuropsychological and neuroanatomical dimensions of ideomotor apraxia. Brain 1992;115:87-107.

2. Zadikoff C, Lang AE. Apraxia in movement disorders. Brain 2005;128:1480-1497.

3. Benson D, Sheremata W, Bouchard R, Segarra J, Proce D, Geschwind N. Conduction aphasia: a clinicopathological study. Arch Neurol 1973;28:339-346.

4. Stamenova V, Roy E, Black S. Limb apraxia in corticobasal syndrome. Cortex 2011;47:460-472.

5. Lee SE, Rabinovici GD, Mayo MC, et al. Clinicopathological correlations in corticobasal degeneration. Ann Neurol 2011; 70:327-340.

6. Litvan I, Agid Y, Goetz C, et al. Accuracy of the clinical diagnosis of corticobasal degeneration: a clinicopathologic study. Neurology 1997;48:119-125.
7. Mathew R, Bak TH, Hodges JR. Diagnostic criteria for corticobasal syndrome: a comparative study. J Neurol Neurosurg Psychiatry 2012;83:405-410.

8. Geschwind MD, Shu H, Haman A, Sejvar JJ, Miller BL. Rapidly progressive dementia. Ann Neurol 2008;64:97-108.

9. Soliveri P, Monza D, Paridi D, et al. Cognitive and magnetic resonance imaging aspects of corticobasal degeneration and progressive supranuclear palsy. Neurology 1999; 53:502-507.

10. Caviness JN. Pathophysiology and treatment of myoclonus. Neurol Clin 2009;27:757-777.

11. Wong JC, Chow TW, Hazrati LN. Adult-onset leukoencephalopathy with axonal spheroids and pigmented glia can present as frontotemporal dementia syndrome. Dement Geriatr Cogn Disord 2011;32:150-158.

12. Freeman SH, Hyman BT, Sims KB, et al. Adult onset leukodystrophy with neuroaxonal spheroids: clinical, neuroimaging and neuropathologic observations. Brain Pathol 2009;19:39-47.

13. Keegan B, Giannini C, Parisi J, Lucchinetti C, Boeve B, Josephs K. Sporadic adult-onset leukoencephalopathy with neuroaxonal spheroids mimicking cerebral MS. Neurology 2008;70:1128-1133.

14. Rademakers R, Baker M, Nicholson AM, et al. Mutations in the colony stimulating factor 1 receptor (CSF1R) gene cause hereditary diffuse leukoencephalopathy with spheroids. Nat Genet 2012;44:200-205. 


\title{
Neurology
}

\author{
Clinical Reasoning: A woman with rapidly progressive apraxia \\ Peter Pressman, Eileen H. Bigio, Darren Gitelman, et al. \\ Neurology 2013;80;e162-e165 \\ DOI 10.1212/WNL.0b013e31828c2eb8
}

This information is current as of April 8, 2013

Updated Information \&
Services

Supplementary Material

\section{References}

Citations

Subspecialty Collections

Permissions \& Licensing

Reprints including high resolution figures, can be found at:

http://n.neurology.org/content/80/15/e162.full

Supplementary material can be found at: http://n.neurology.org/content/supp1/2013/04/07/80.15.e162.DC1 http://n.neurology.org/content/supp1/2013/04/07/80.15.e162.DC2

This article cites 14 articles, 4 of which you can access for free at: http://n.neurology.org/content/80/15/e162.full\#ref-list-1

This article has been cited by 1 HighWire-hosted articles: http://n.neurology.org/content/80/15/e162.full\#\#otherarticles

This article, along with others on similar topics, appears in the following collection(s):

All Movement Disorders

http://n.neurology.org/cgi/collection/all_movement_disorders

Apraxia

http://n.neurology.org/cgi/collection/apraxia

Leukodystrophies

http://n.neurology.org/cgi/collection/leukodystrophies

Information about reproducing this article in parts (figures,tables) or in its entirety can be found online at:

http://www.neurology.org/about/about_the_journal\#permissions

Information about ordering reprints can be found online:

http://n.neurology.org/subscribers/advertise

Neurology ${ }^{\circledR}$ is the official journal of the American Academy of Neurology. Published continuously since 1951, it is now a weekly with 48 issues per year. Copyright @ 2013 American Academy of Neurology. All rights reserved. Print ISSN: 0028-3878. Online ISSN: 1526-632X.

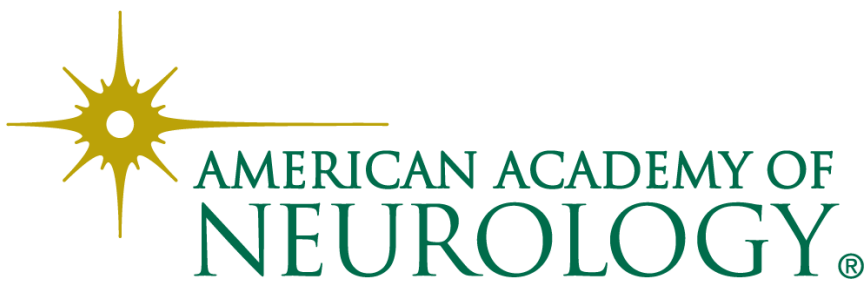

